
Registers

\title{
Editorial Comment: 2014 Meeting of The International Society of Arthroplasty Registers
}

\author{
Henrik Malchau MD, PhD, Martyn L. Porter FRCS
}

$\mathrm{T}$ he International Society of Arthroplasty Registers (ISAR) was formed in 2004 at the American Academy of Orthopaedic Surgeons annual meeting. Forty national, regional, or institutional registries are presently ISAR members (11 full and 29 associate). The goal of ISAR is to "utilize the strength of cooperation and sharing of information and further enhance the capacity of individual registries to meeting their own aims and objectives. The society is involved in the development of frameworks to encourage collaborative activities and provides a support network for established and developing registries" [3].

The authors certify that they, or any members of their immediate families, have no funding or commercial associations (eg, consultancies, stock ownership, equity interest, patent/licensing arrangements, etc.) that might pose a conflict of interest in connection with the submitted article. All ICMJE Conflict of Interest Forms for authors and Clinical Orthopaedics and Related Research ${ }^{\mathbb{R}}$ editors and board members are on file with the publication and can be viewed on request.

The opinions expressed are those of the writers, and do not reflect the opinion or policy of $C O R R^{\circledR}$ or The Association of Bone and Joint Surgeons ${ }^{\circledR}$.
Arthroplasty registries play an important role in patient safety and quality improvement. The value of registries is not simply to monitor implant performance but drive improvements and quality of care. This is achieved by providing feedback to surgeons, hospitals and regulatory bodies to facilitate change in practice.

It is important to appreciate that registries in themselves cannot prevent catastrophic or unexpected events, but what they can do is pick up the signals of failure at a much earlier stage than otherwise would have occurred. A good example of this was the introduction of implants with metal-on-metal

H. Malchau MD, PhD

Harvard Medical School, Boston, MA, USA

H. Malchau MD, PhD

Harris Orthopaedic Laboratory,

Massachusetts General Hospital, Boston, MA, USA

\section{L. Porter FRCS ( $\square)$}

The Centre for Hip Surgery, Wrightington Hospital, Hall Ln, Appley Bridge, Wigan, Lancashire WN6 9EP, UK e-mail: martynporter@hipkneeclinic.com

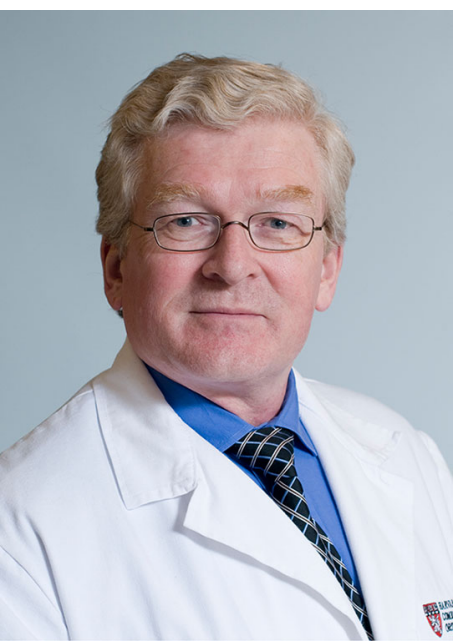

Henrik Malchau MD, PhD

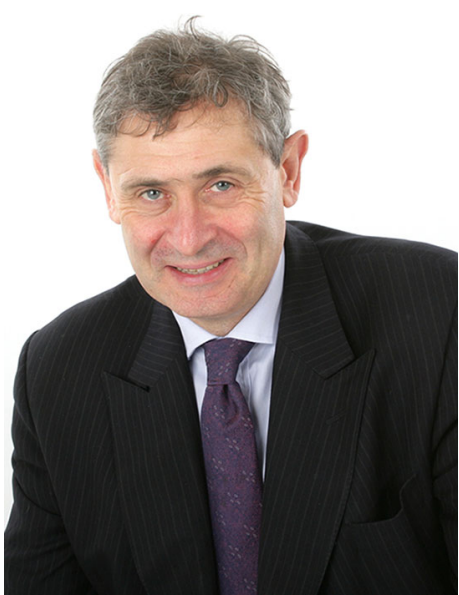

Martyn L. Porter FRCS 


\section{Symposium: 2014 Meeting of International Society of Arthroplasty Registers}

articulations and the detection of statistically inferior outcomes within 5 years. This early detection and dissemination of information resulted in the change of implant selection and saved many patients from receiving an inferior device [4].

Many registries already support research and postmarket surveillance but new methodologies are emerging [1]. Under such a rubric, clinical trials on new and established techniques could be "nested" in national and regional registries with high coverage and data completeness. (Nesting refers to a more detailed or enhanced data set. For example, a collection of radiographs to obtain more data on the implant or intervention under observation). This process, referred to as "Beyond Compliance" [2] has already been established in the United Kingdom. This kind of enhanced data collection will add value to registries and reduce cost compared to more traditional methods of postmarket surveillance and research.

As ISAR has grown and expanded it held its first international congress in Norway in 2012 and papers from this edition of $\operatorname{CORR}^{\circledR}$ were presented during the Third Congress in Boston, MA, USA in 2014. These papers cover a broad area of registry research including refinement and reliability of patientrelated outcomes data, identifying risk factors for readmission, methodology of establishing revision risk, and the fate of the revised resurfacing.

\section{References}

1. Malchau H, Graves SE, Porter M, Harris WH, Troelsen A. The next critical role of orthopedic registries. Acta Orthop. 2015;86:3-4.

2. Donnell S, Kay P. Beyond compliance: UK surgeons present voluntary hip and knee replacement initiative. Available at: http://www.medicalplas ticsnews.com/opinion/beyond-compli ance/. Accessed June 23, 2015.

3. International Society of Arthroplasty Registers. Available at: http://www.is arhome.org/. Accessed June 23, 2015.

4. Smith AJ, Dieppe P, Vernon K, Porter ML, Blom AW. Failure Rates of Stemmed Metal-on-Metal Hip Replacements: Analysis of data from the National Joint Registry of England and Wales. The Lancet. 2012;379:11991204. 